\title{
Thermodynamic analysis of high pressure hydrogen gas refueling system with turbo-expanders
}

\author{
Jun YOSHIDA*, Eito MATSUO**, Yasuyuki TAKATA***,**** and Masanori MONDE***** \\ * Hitachi Plant Mechanics Co., Ltd. \\ 794 Higashitoyoi, Kudamatsu-city, Yamaguchi 744-0002, Japan \\ E-mail: Jun.yoshida.gz@hitachi.com \\ ** Archiveworks. Co., Ltd. \\ 1-2693-46 Higashiomura, Omura-city, Nagasaki 856-0032, Japan \\ *** Department of Mechanical Engineering Science, Kyushu University \\ 744 Motooka, Nishi-ku, Fukuoka 819-0395, Japan \\ **** International Institute for Carbon-Neutral Energy Research, Kyushu University \\ ***** Saga University \\ 1 Honjyo-cho, Saga-city, Saga 840-8502
}

Received: 30 August 2018; Revised: 11 December 2018; Accepted: 5 April 2019

\begin{abstract}
This paper introduces a new hydrogen refueling system with a micro-scale hydrogen turbo-expander that enables us to replace a conventional low temperature refrigerator. From the process simulation of hydrogen refueling to the tank of a typical Fuel Cell Vehicle (FCV), the system is thermodynamically verified to be capable of refueling $5 \mathrm{~kg}-\mathrm{H}_{2}$ within 3 minutes by the direct expansion in the micro-scale hydrogen turbo-expander. For the realization of this new concept, a process design approach of a high pressure hydrogen refueling system with the micro-scale hydrogen turbo-expander is described. In this process design, a turbine-compressor type is adopted to the micro-scale hydrogen turbo-expander unit, and an extracted power from the turbine side is consumed as a compressor power which is equipped on the opposite side of the turbine rotor. As a consequence of the thermodynamic analysis and simulation for the proposed system including the turbo-expander with adiabatic efficiency around $65 \%$, it reveals that the new system provides some significant advantages compared with the conventional process. From a feasible investigation of this system, several advantageous features such as 1) high energy conservation, 2) compactness, 3) initial cost and operation cost, and, 4) system expandability (modification for shorter time refueling) are also described when it is compared with the existing system.
\end{abstract}

Keywords: Expansion turbine, Hydrogen, Pre-cooling process, Hydrogen thermal properties

\section{Introduction}

According to a global rapid growth of FCV's (Fuel Cell Vehicles) market, Hydrogen Refueling Station (HRS) is to be constructed rapidly in order to accelerate its commercialization as an indispensable social infrastructure of FCV. At present, in Japan, approx. 100 HRS plants have been newly constructed and started thier commercial operation up to fiscal year of 2017 .

In order to accelerate construction of the HRS steadily with commercial competitiveness, further cost down and further improvement are required immediately. Particularly a drastic total cost down for HRS are indispensable for their deployment, i.e. cost down of initial hardware, for site erection and installation, and daily operation. However, even the latest constructed HRS process is designed by adopting conventional mechanical components such as pre-cooling system with refrigerators, which has a limitation for further cost improvement.

In general, the HRS is composed of three main systems, such as high pressurized hydrogen gas accumulator system 
up to $82 \mathrm{MPa}$ in Japan, pre-cooling system, and dispensing system, regardless of whether the HRS is on-site or off-site for hydrogen generation. The pre-cooling system cools the hydrogen gas down to its temperature of around $-40{ }^{\circ} \mathrm{C}$ to satisfy the safety regulation that the hydrogen temperature should be below $85^{\circ} \mathrm{C}$ at the tank during the hydrogen refueling process. This pre-cooling system is designed with the conventional heat process technologies of industrial brine circulating refrigeration system with heat exchangers, which requires electric power to drive a refrigerator maintaining the brine bath temperature approximately around $-45{ }^{\circ} \mathrm{C}$. One of the highest requirements of HRS's operational performance is to ensure its full-refueling within around 3 minutes safely, that provides comparable convenience to an existing petrol-fuelled vehicle. For this requirement, the pre-cooling system has been equipped to the HRS. Several advanced research and engineering on hydrogen refueling process have been performed and demonstrated (Monde, 2006 and 2012), and then a detailed analysis for heat transfer characteristics of the fuel tanks of FCV during high pressure gas refueling is also reported (Kuroki 2018, Monde 2013, and Woodfield 2008).

The present study proposes an innovative system of hydrogen refueling without the conventional pre-cooling apparatus by introducing a turbo-expansion process that produces low temperature hydrogen at the system outlet. The thermodynamic analysis of the turbo-expansion process and its potential feasibility are described. This system provides higher energy conservation without $-45^{\circ} \mathrm{C}$ class refrigerators, which realize electricity saving almost 87 percent of precooling refrigerator for daily operation.

The designed turbo-expander corresponding to the typical standard HRS, namely the turbine rotor has quite small diameter with high speed rotation, which provides considerable compactness comparing to the conventional pre-cooling systems. This means the new system is able to reduce not only the initial cost but also erection and construction cost respectively, since the new system provides much smaller foot-print configurations compared to the conventional precooling system. In addition, this system would be suitable for refueling a large amount of hydrogen for larger vehicle such as a FC-Bus or Truck than the light FCV. Furthermore, the new system has a potential for the other industrial applications to every hydrogen gas refueling process and facilities, such as hydrogen gas refueling station for individual fuel tank for hydrogen fuel cell network in the future.

In this paper, by utilizing thermal property database of high pressure normal gaseous hydrogen (Sakoda, 2014), the system investigation of new concept HRS with a hydrogen turbo-expander is performed, which eliminates conventional pre-cooler and $-45^{\circ} \mathrm{C}$ class refrigerators. In order to meet a requirement of low temperature restriction of refueling hydrogen in the present refueling protocol, we install a cold accumulator unit at the outlet of the turbine. The cold accumulator unit works as a low temperature thermal buffer to maintain the hydrogen temperature not being about $40{ }^{\circ} \mathrm{C}$.

\section{Conventional system}

The present HRS plant is typically composed of a high pressure hydrogen accumulator system including hydrogen compressor units and high pressure storage vessels, a pre-cooling system including a pre-cooling heat exchanger and a refrigerator, and a dispensing system as shown in Fig. 1(a). Figure 1(b) focuses on the part of pre-cooling system in Fig. 1(a) as a schematic flow diagram.

During the hydrogen refueling into the FCV tank, the tank temperature should be restricted to maintain lower than $85^{\circ} \mathrm{C}$ due to the design limit of the bonding material on resin-forced layers of the tank. In order to satisfy this requirement, prior to refueling, the hydrogen gas is cooled down to below $-40{ }^{\circ} \mathrm{C}$ in a pre-cooler, resulting into temperature rise lower than $85{ }^{\circ} \mathrm{C}$ at any refueling condition specified in SAE-J2601 (2016). This temperature rise is brought by an adiabatic compression of hydrogen refuelled into the tank. The pre-cooling is performed by a heat exchanger at the pre-cooler unit with the cold brine fluid (around $-43 \sim-45{ }^{\circ} \mathrm{C}$ ) chilled by a refrigerator. For example, the pre-cooling system for HRS with a typical capacity of flow rate of $300 \mathrm{Nm}^{3} /$ hour requires around a $30 \sim 43 \mathrm{~kW}$ class refrigerator for cooling a hydrogen gas about $-40^{\circ} \mathrm{C}$. The existing pre-cooling system consists of several machineries such as refrigerator, condenser cooler, brine pump and brine piping, which makes the system more complicated and relatively wide foot prints shall be needed as shown in Fig. 1(b).

In pre-cooling operation scenario, the conventional system requires a periodical pre-operation of the refrigerator intermittently in order to keep the temperature of fluid brine bath tank around below $-43 \sim-45^{\circ} \mathrm{C}$ during a stand-by waiting time 


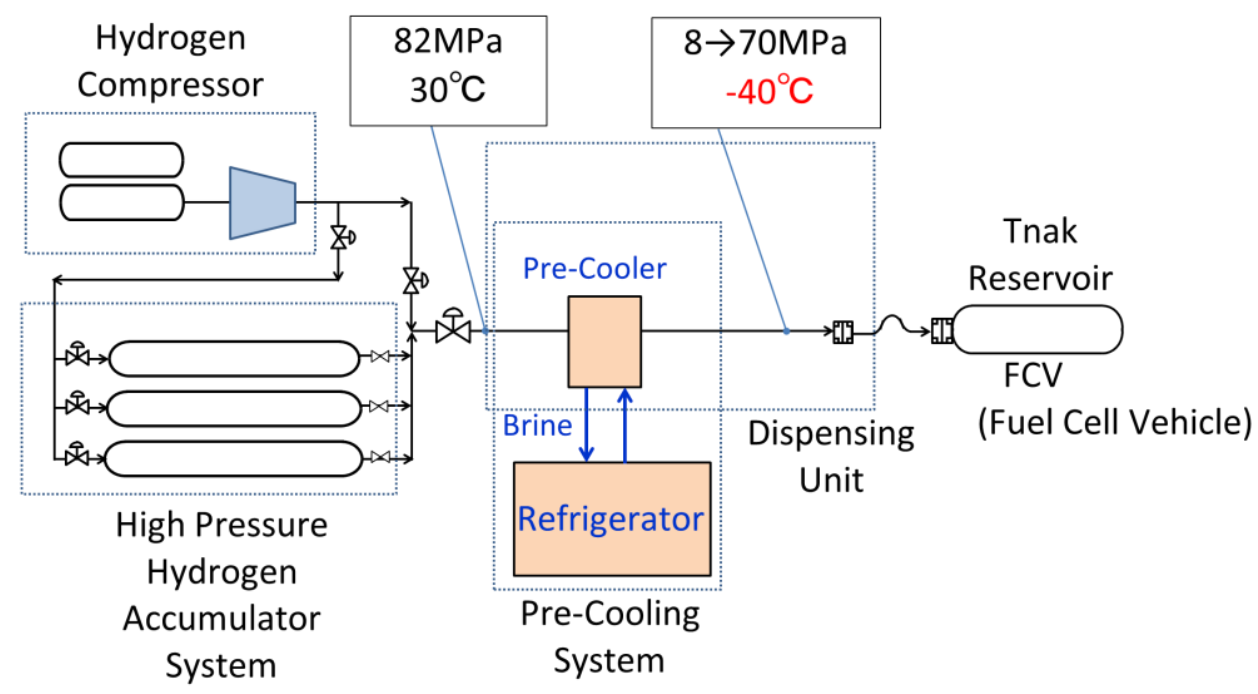

Fig. 1(a) Conventional major components of hydrogen refueling stand

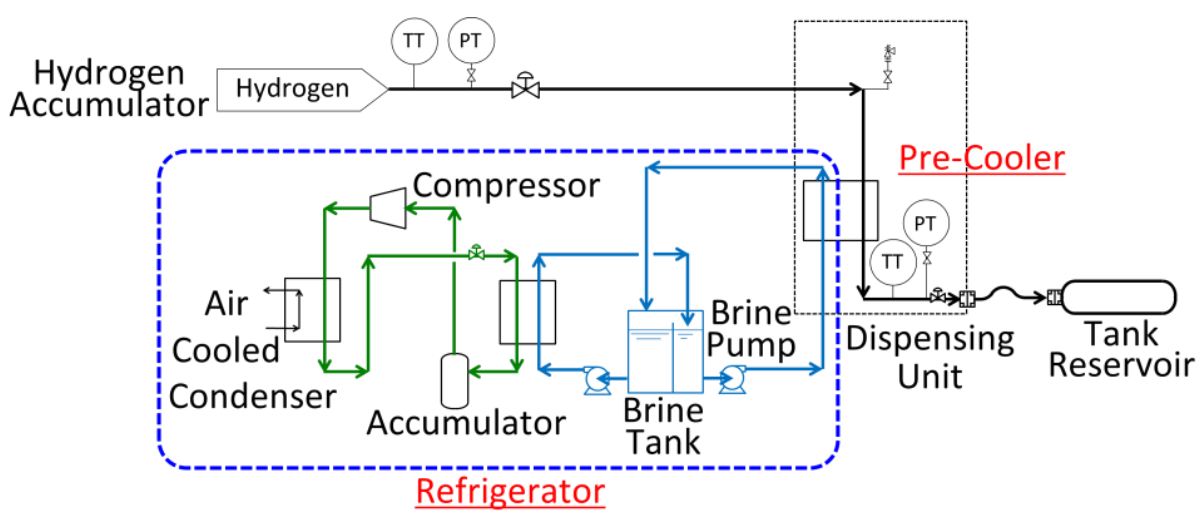

Fig. 1(b) Conventional process of pre-cooling system

\section{New process for pre-cooling system with a turbo-expander}

Figure 2 shows a proposed hydrogen refueling system using a turbo-expander in place of conventional pre-cooling system. Obviously, the new system is quite simpler than the conventional one (Fig. 1(b)). The turbo-expander provides a cryogenic enthalpy drop by extracting an expansion work from the fluid resulting in outlet gas temperature decrease. The cooling of hydrogen is done by its own change of state and not by heat transfer. Therefore, the new system can obtain cold hydrogen instantaneously compared with the conventional system. This expansion process is performed by high-speed rotation of a turbine rotor, without any external energy input such as electrical motors for conventional pre-cooling system. Therefore, the new system enables us to conserve the energy input for operation, and this simple flow configuration provides much more compactness of the equipment, which conducts to attain the cost down of the system totally.

For the new process a turbine-compressor type is adopted to the turbo-expander unit. An extracted thermodynamic power from the turbine side is consumed as a compression power which is equipped on the opposite side of the turbine rotor. This turbine-compressor method also provides advantages to the process with higher expansion ratio to the turbine inlet pressure. In the detail design of the turbo-expander unit, the turbine rotor should have a very small diameter with ultra-high circumferential velocity to ensure small flow rate and high expansion ratio of hydrogen. When we design this system for the typical standard capacity of HRS, we determine the specification of the hydrogen turboexpander as $10 \mathrm{~mm} \phi$ in diameter and over 1,000 krpm in rotating speed approximately. The type of the turbine is 
categorized as a gas bearing supported inward type micro turbo-expander.

For a typical proccess, in accordance with Fig. 2, hydrogen is supplied with a typical initial flow rate of around 33 $\mathrm{g} / \mathrm{s}$ (maximum) from the accumulator unit whose pressure and temperature are around $82 \mathrm{MPa}$ and $30{ }^{\circ} \mathrm{C}$, respectively. The hydrogen is induced to the inlet of compressor impeller that is equipped at the opposite side of the turbine rotor and, then, it is compressed up to around $104 \mathrm{MPa}$ and cooled in an after-cooler down to around temperature $10 \sim 20{ }^{\circ} \mathrm{C}$ by a cooling source, such as air-cooled cooler or chilled water. The hydrogen is expanded by the turbine directly to extract expansion work as an ultra-high rotating speed around 1,000 krpm as designed. The typical T-s diagram of the turbine process are shown in Figs. 3(a) and (b) as the initial and intermediate cases during refueling, respectively. In both figures, the induced hydrogen gas source is maintained at $82 \mathrm{MPa}$ and $30^{\circ} \mathrm{C}$ from the hydrogen accumulator. Fig. 3(a) shows a typical status at the initial stage in high expansion ratio that provides higher turbine inlet pressure around 102 $\mathrm{MPa}$ at outlet of the compression impeller. In the meanwhile, Fig. 3(b) shows a typical example of intermediate stage in intermediate expansion ratio that the turbine inlet pressure is decreased in accordance with decreasing of turbine power. In order to make a hydrogen supply temperature over $-40{ }^{\circ} \mathrm{C}$, hydrogen gas is induced to a cold accumulator unit for satisfying the present refueling protocol. In this simulation, an overall turbine adiabatic efficiency is set $65 \%$ and, which is attainable in the conventional cryogenic process plant.

Through the dispensing unit, the expanded hydrogen is measured and regulated to meet the refueling protocol. In conclusion, the turbine unit can be designed as to be compact around $85 \%$ reduction of the machine hard volume ratio against to the conventional system. Figure 4 shows a turbine expansion system with a metric dimension in the unit. Furthermore, the proposed turbine system has a possibility to shorten the refueling time by arranging several turbine units in parallel for future application design. This means the turbine system has an advantageous possibility for the easy enlargement or expandability of the capacity of the HRS with lower cost.

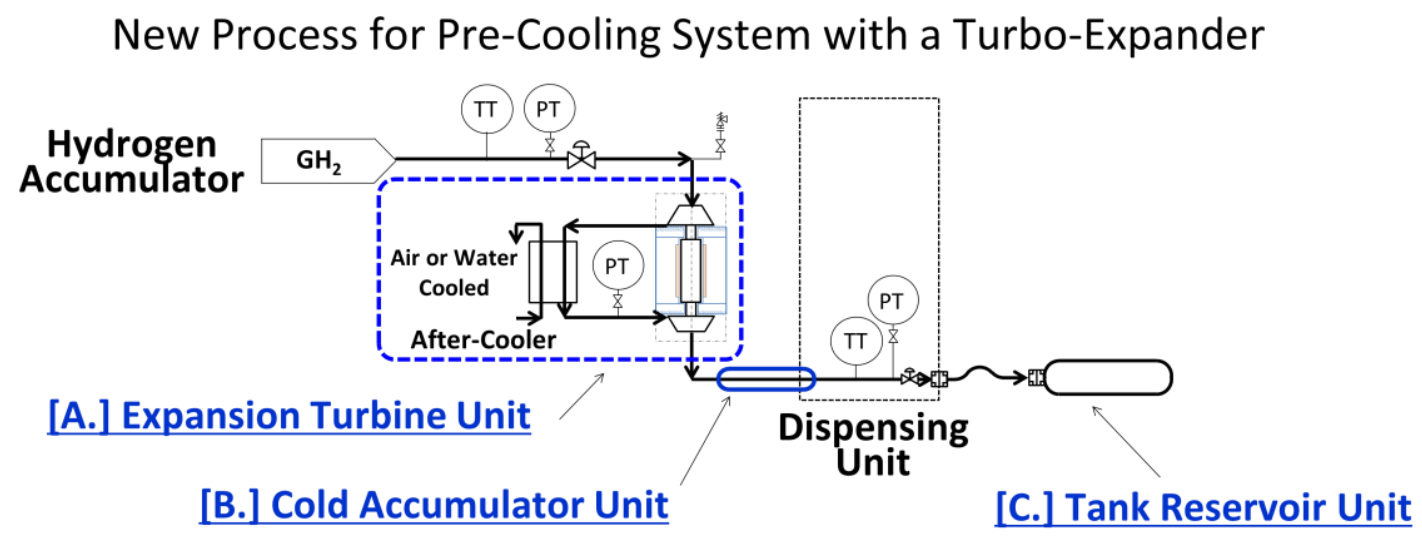

Fig. 2 Schematic flow diagram for new process with turbo-expander (and cold accumulator unit)

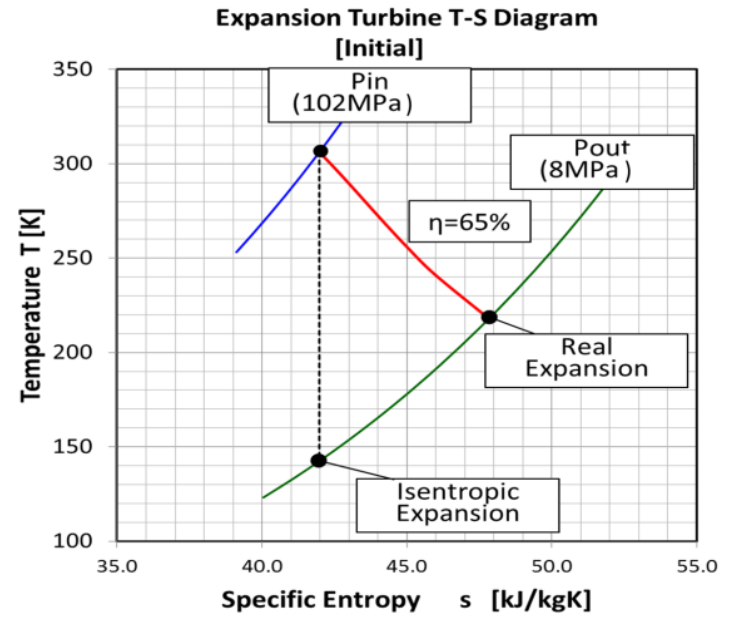

Fig. 3(a) T-s diagram of expansion turbine for an expansion ratio: $102 / 8 \mathrm{MPa}$

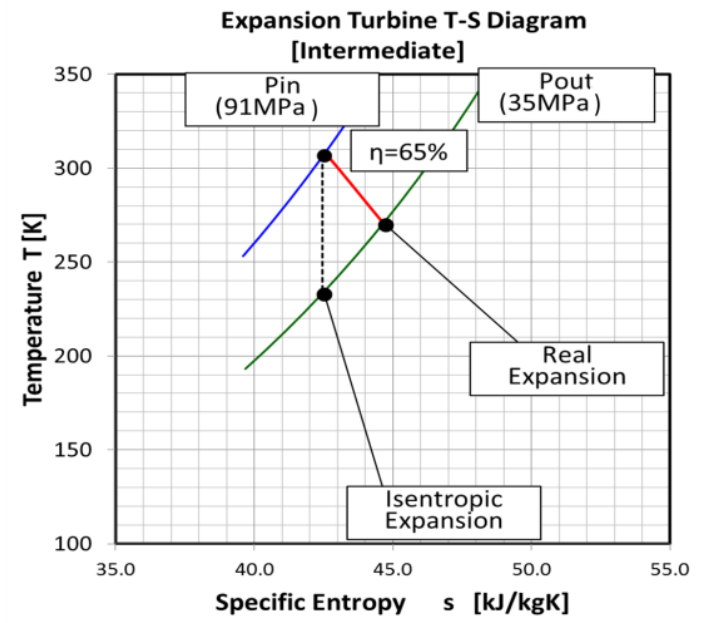

Fig. 3(b) T-s diagram of expansion turbine for an expansion ratio: $91 / 35 \mathrm{MPa}$ 
Yoshida, Matsuo, Takata and Monde, Mechanical Engineering Journal, Vol.6, No.3 (2019)

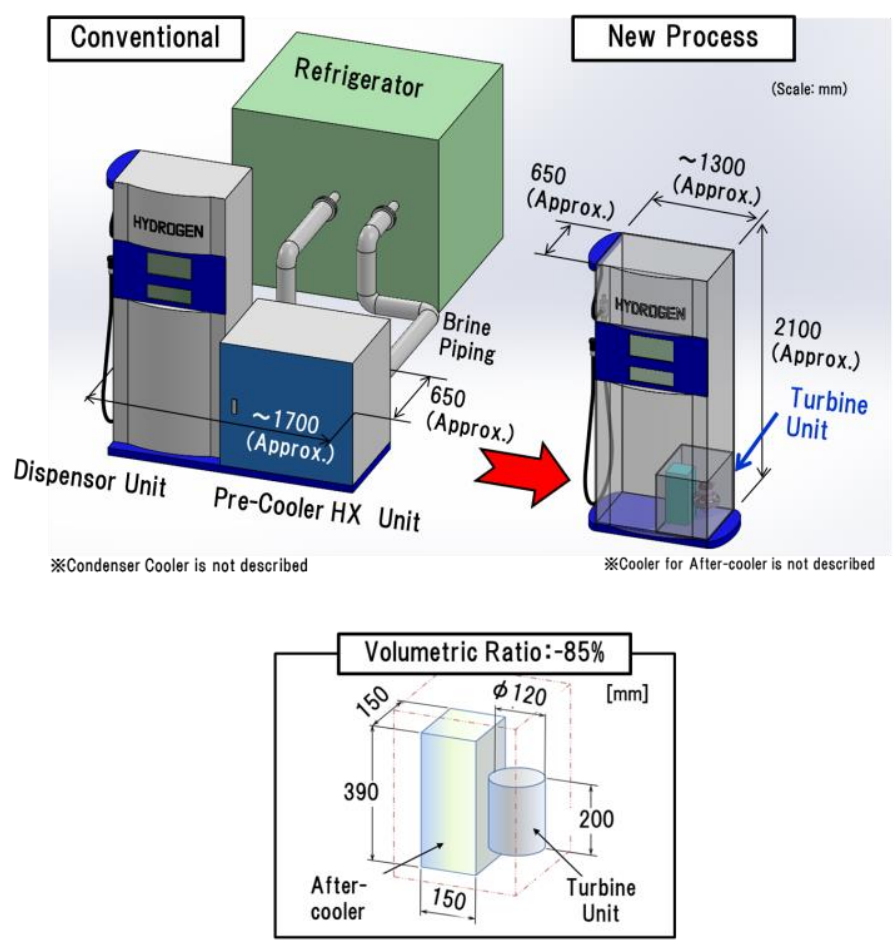

Fig. 4 Schematic view of the system 


\section{Thermodynamic process simulation}

\subsection{Simulation model and conditions}

Regarding to the standard refueling protocol, so far, several refueling process simulations have been performed systematically using $\mathrm{H}_{2}$ Fill software which has been developed to analyze the temperature and pressure in the tank during refueling process of hydrogen by Monde et al. (Monde 2006, 2012, 2013, and Woodfield 2008). By using the same simulation codes (Monde 2013), linked with thermal properties of hydrogen (Sakoda 2014), thermodynamic simulation for the new refueling system with the turbine can be totally evaluated. For the new proposed system, the process calculation is performed from [A.] expansion turbine unit to [C.] tank reservoir as shown in Fig. 2 consistently. A simulation model and its calculation flow chart are shown in Fig 5(a), (b) and Fig.6, respectively. The simulation model is composed of sequential three main process parts, [A.] the expansion turbine process, [B.] the cold accumulator unit process, and [C.] tank refueling process. For each process, temperature and pressure are calculated with every calculation time $\tau$ by each time steps $\Delta \tau$ continuously.

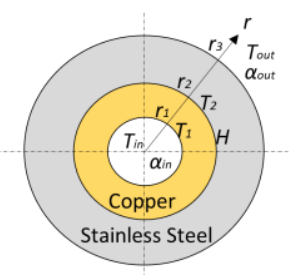

For each sectional view
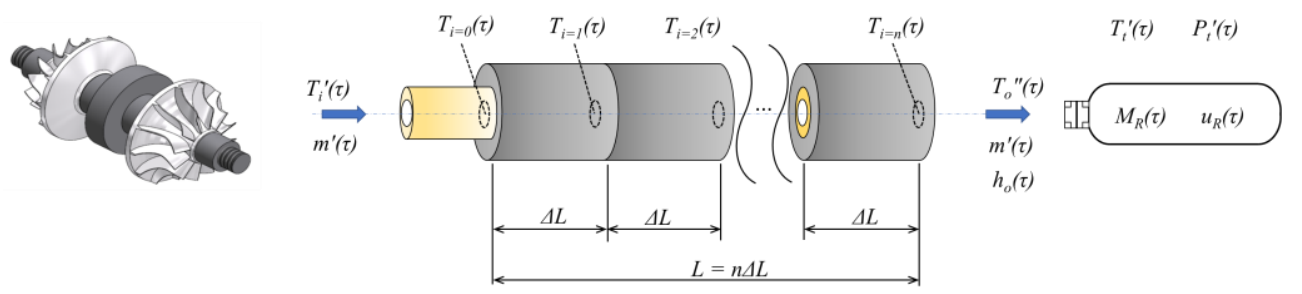

[A.] Expansion Turbine Unit

[B.] Cold Accumulator Unit

[C.] Tank Reservoir Unit

Fig. 5(a) Simulation model in case with a cold accumulator unit

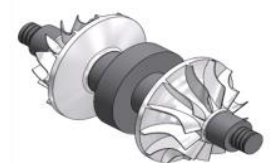

[A.] Expansion Turbine Unit

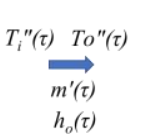

$h_{0}(\tau)$

\section{[C.] Tank Reservoir Unit}

Fig. 5(b) Simulation model in case with a cold accumulator unit

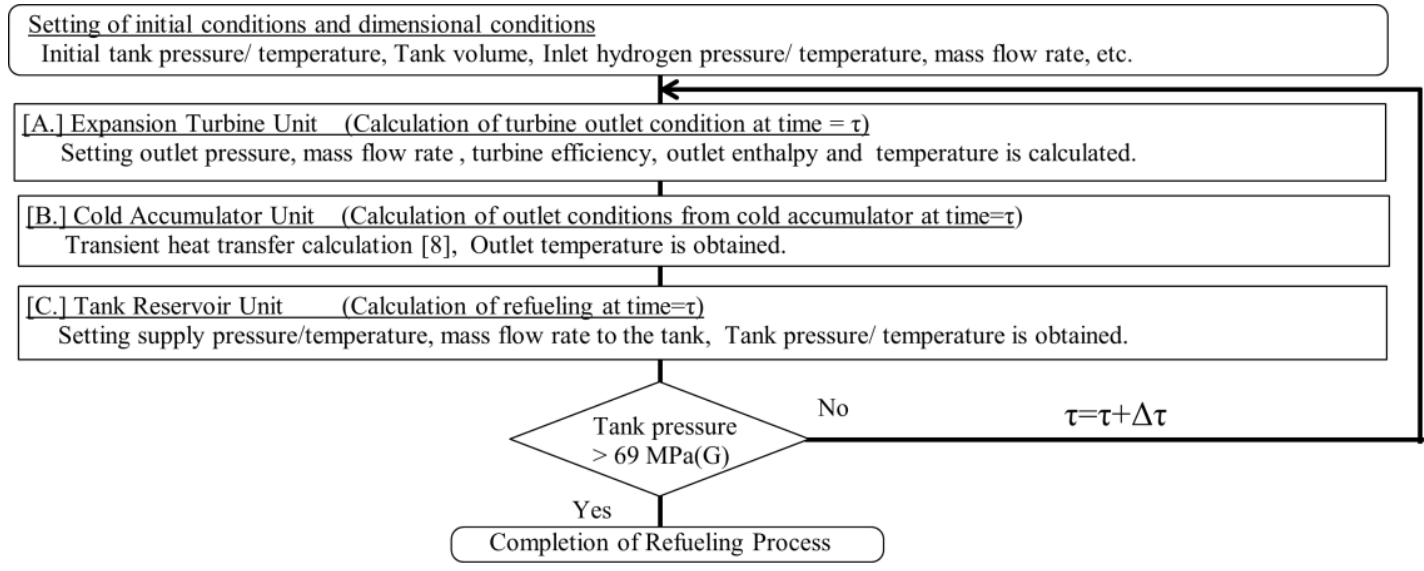

Fig. 6 Flow chart to calculate tank pressure/ temperature 


\subsubsection{Expansion turbine unit}

In the expansion turbine process, enthalpy of turbine outlet is calculated to meet the condition specified from the pressure at the refueling tank for every calculation seconds consistently. An outlet condition is calculated from the inlet conditions and turbine efficiency.

Obviously, the expansion ratio of the turbine changes approximately from 13 to 1.2 with time in accordance with an increasing of tank pressure during its refueling. Therefore, the turbine outlet conditions are changed continuously up to fulfilment, enthalpy drop decreases by elapsed time resulting from the changing of turbine rotation speed and turbine efficiency etc. This means turbine outlet temperature changes during refueling operation.

\subsubsection{Cold accumulator unit}

The turbine outlet temperature will go down under $-40{ }^{\circ} \mathrm{C}$ in the initial stage of the refueling operation, around 30 seconds, in a typical case, as shown in Fig. 3(a). This temperature fall is not accepted in the present refueling protocols, even though the final temperature in the tank surely becomes lower than $85^{\circ} \mathrm{C}$ in the new process. For the proposed new process, therefore, a cold accumulator that controls the hydrogen temperature over $-40{ }^{\circ} \mathrm{C}$ would be needed for practical use to meet the requirement of refueling protocol. Figure 5 shows a tube type cold accumulator model, which will be installed at the outlet of turbine to relax an exceeded temperature over $-40{ }^{\circ} \mathrm{C}$.

The proposed accumulator consists of Copper inner tube and Stainless steel outer tube as shown in Fig. 5(a). These dimensions are designed as $3.0 \mathrm{~mm} \phi / 6.3 \mathrm{~mm} \phi$ for inner tube and $6.3 \mathrm{~mm} \phi / 14.3 \mathrm{~mm} \phi$ for outer tube, respectively. The inner tube with its dimension can be smoothly connected to the downstream pipe line.

A thermal simulation is performed by solving a transient heat conduction in the accumulator in connection with turbine outlet temperature and then by calculating the temperature at the exit of the accumulator. A procedure of the simulation is firstly to solve these transient heat transfer for two annular tubes and secondly to calculate heat balance for a length of flow direction. The following transient heat conduction equations for inner and outer tubes are numerically solved with initial and boundary conditions.

$$
\begin{array}{lll}
\frac{\partial T_{1}}{\partial t}=a_{1} \frac{1}{r}\left(\frac{\partial}{\partial r}\left(r \frac{\partial T_{1}}{\partial r}\right)\right) & \left(r_{1}<\mathrm{r}<r_{2}\right) & \text { (Inner tube) } \\
\frac{\partial T_{2}}{\partial t}=a_{2} \frac{1}{r}\left(\frac{\partial}{\partial r}\left(r \frac{\partial T_{2}}{\partial r}\right)\right) & \left(r_{2}<\mathrm{r}<r_{3}\right) & \text { (Outer tube) }
\end{array}
$$

For initial condition:

$$
T_{1}=T_{2}=T_{\text {out }} \neq T_{\text {in }} \quad(\mathrm{t}=0)
$$

For boundary conditions:

$$
\begin{array}{ll}
-\lambda_{1} \frac{\partial T_{1}}{\partial r}=h_{i n}\left(T_{i n}-T_{1}\right) & \left(\mathrm{r}=r_{1}\right) \\
-\lambda_{1} \frac{\partial T_{1}}{\partial r}=-\lambda_{2} \frac{\partial T_{2}}{\partial r} \quad, \quad T_{1}=T_{2} & \left(\mathrm{r}=r_{2}\right) \quad \text { or } \\
-\lambda_{1} \frac{\partial T_{1}}{\partial r}=H\left(T_{1}-T_{2}\right)=-\lambda_{2} \frac{\partial T_{2}}{\partial r} & \left(\mathrm{r}=r_{2}\right)
\end{array}
$$

where $H$ is a thermal conductance between inner and outer tubes. It may be noted to mention that a small value of $H$ serves as a large thermal resistance and then a large value beyond $H=10^{5}\left[\mathrm{~W} /\left(\mathrm{m}^{2} \mathrm{~K}\right)\right]$ corresponds the perfect conductance.

$$
-\lambda_{2} \frac{\partial T_{2}}{\partial r}=h_{\text {out }}\left(T_{2}-T_{\text {out }}\right) \quad\left(\mathrm{r}=r_{3}\right)
$$

The temperatures for two annular tubes are given by $T_{1}(r, t)$ and $T_{2}(r, t)$ respectively. The analytical solutions for equations (1) and (2) become as follows.

$$
\begin{aligned}
& T_{1}(r, t)=\sum_{n=1} \exp \left(-a_{1} \alpha_{1, n}^{2} t\right) \frac{B r_{1} \theta_{0}}{\frac{\alpha_{1, n}}{2} D_{1, n}}\left\{\left(\frac{\overline{a_{1,1}}}{a_{1,2}}\right) *\left(J_{0}\left(\alpha_{1, n} r\right), Y_{0}\left(\alpha_{1, n} r\right)\right)\right\}+T_{S=0}(r)+T_{\text {out }} \\
& T_{2}(r, t)=\sum_{n=1} \exp \left(-a_{2} \alpha_{2, n}^{2} t\right) \frac{B r_{2} \theta_{0}}{\frac{\alpha_{2, n} D_{2, n}}{2}}\left\{\left(\frac{\overline{a_{1,1}}}{a_{1,2}}\right) *\left(J_{0}\left(\alpha_{1, n} r\right), Y_{0}\left(\alpha_{1, n} r\right)\right)\right\}+T_{S=0}(r)+T_{\text {out }}
\end{aligned}
$$


In order to calculate numerically the transient temperatures $T_{1}$ and $T_{2}$, the first to the fourth terms for $\alpha_{1, n}$ and $\alpha_{2, n}$ are used. The details for each parameter in Eqs. (5-a) and (5-b) will be described in Appendix.

The temperature changes along the flow direction due to heat transfer between hydrogen and tube wall. Therefore, the tube is divided into several domains for numerical simulation. The length for each section changes from $\Delta L=0.1 \mathrm{~m}$ to $0.4 \mathrm{~m}$ or larger depending on the accuracy of the exit temperature. In most cases, the length of $\Delta L=0.1 \mathrm{~m}$ is sufficient to evaluate the temperature with a convergence criterion of $10^{-5}$. For each section of $\Delta L$, the tube wall temperature is assumed as constant, and outlet hydrogen temperature is obtained from each heat balance.

This section is based on results obtained from a project subsidized by the New Energy and Industrial Technology Development Organization (NEDO).

\subsubsection{Refueling reservoir unit (refueling to tank)}

Simulation for this process is preformed independently by using former procedure (Monde 2013). Basic heat balance equation in the refueling tank is described as follows.

$$
\frac{d Q}{d \tau}+\mathbf{m}^{\prime}(\tau) \cdot h_{o}^{\prime}(\tau)=\frac{d\left(M_{R}(\tau) \cdot u_{R}(\tau)\right)}{d \tau}
$$

In Eq.(6), $\mathrm{Q}$ is a heat transfer between hydrogen and tank wall. The hydrogen temperature can be calculated through $\mathrm{H}_{2}$ Fill* software based on Eq. 6. (Monde 2012, 2013, and Woodfield 2008). The inlet hydrogen condition is linked from the outlet condition for each calculation time $\tau$.

\subsection{Simulation result}

The process simulation was performed by each time interval linking each calculated condition values consistently. The tank volume of $150 \mathrm{~L}$, which is almost equivalent to the standard protocol, was set as that of typical middle class $\mathrm{FCV}$, and then an initial pressure level is set as $8 \mathrm{MPa}$ tentatively, and an initial temperature as $20^{\circ} \mathrm{C}$. The turbine work can be calculated from the adiabatic enthalpy drop and the mass flow rate of each period, and the turbine work is converted into the compression power at the compressor side which is equipped on the opposite side of the turbine impeller, resulting the hydrogen pressure and temperature at the compressor outlet point induced into the after cooler. The calculation was combined with the tank refueling part and continued until the tank pressure becomes $70 \mathrm{MPa}$ to the completion of refueling. The calculation is performed by a typical refueling scenario for middle class FCV, and $5 \mathrm{~kg}$ of hydrogen should be filled within 3 minutes. In this calculation, turbine flow rate designed is set as $33 \mathrm{~g} / \mathrm{s}$ for initial expansion ratio and overall efficiency is assumed to be $65 \%$, which is attainable in the cryogenic process plant.

Figure 7(b), for an example, shows the temperature at the exit of accumulator with a length of $4.0 \mathrm{~m}$ under the condition of ambient temperature $T_{\text {out }}=20^{\circ} \mathrm{C}$, heat transfer coefficients of $10 \mathrm{~W} / \mathrm{m}^{2} \mathrm{~K}$ on the outside and $40000 \mathrm{~W} / \mathrm{m}^{2} \mathrm{~K}$ on the inside, perfect conductance between two tubes and then the inlet temperature of $T_{i n}$, which just corresponds to one at the exit of the turbine with the efficiency of $65 \%$.

It is noticed from Figs.7(a) and (b) that the temperature at the exit of the accumulator almost becomes higher than $40{ }^{\circ} \mathrm{C}$ which obeys the refueling protocol, while the inlet temperature in the early stage of fueling is lower than $-40{ }^{\circ} \mathrm{C}$. In addition, Figs.7(a) and (b) tells us that the temperature in the tank still satisfies the regulation being lower than $85^{\circ} \mathrm{C}$, in spite of shorter refueling time of $130 \mathrm{~s}$ compared with that of around $180 \mathrm{~s}$ in an conventional HRS.

It should be mentioned finally that although the simulation has been carried out based on the perfect conductance between copper and stainless-steel tubes, an effect of the thermal conductance between them will be evaluated for practical application of this system. 


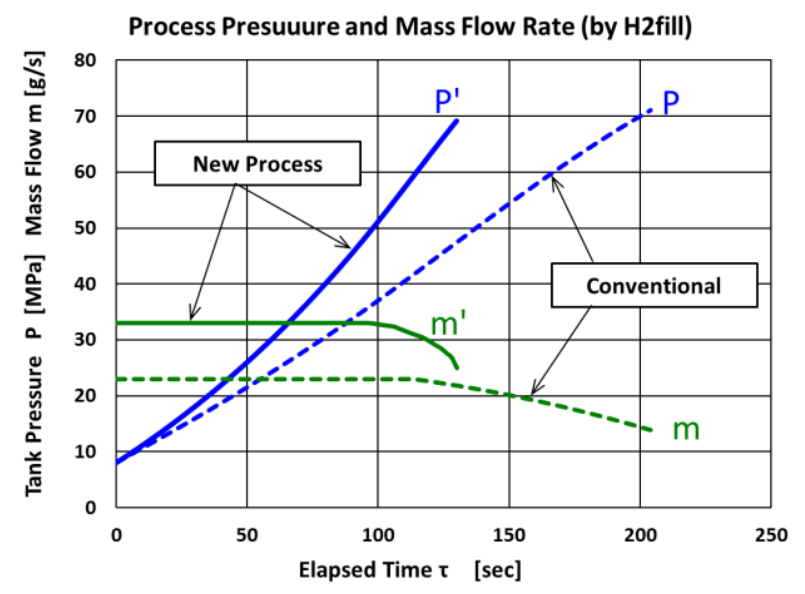

Fig. 7(a) Tank pressure and mass flow rate, refueling condition for

$P, P^{\prime}:$ Tank gas pressure $[\mathrm{MPa}] \quad m, m^{\prime}:$ mass flow rate of refueling hydrogen $[\mathrm{g} / \mathrm{s}]$

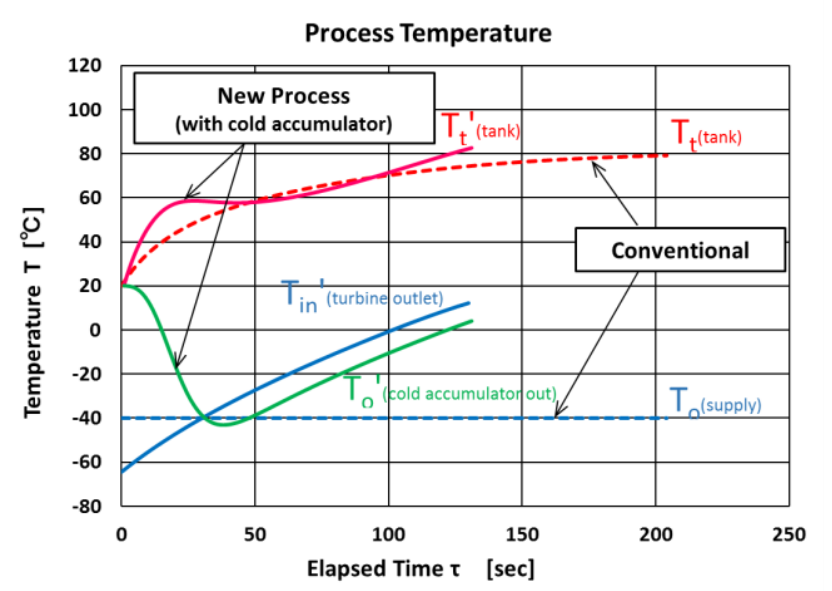

Fig. 7(b) Refueling process temperatures in case with cold accumulator unit

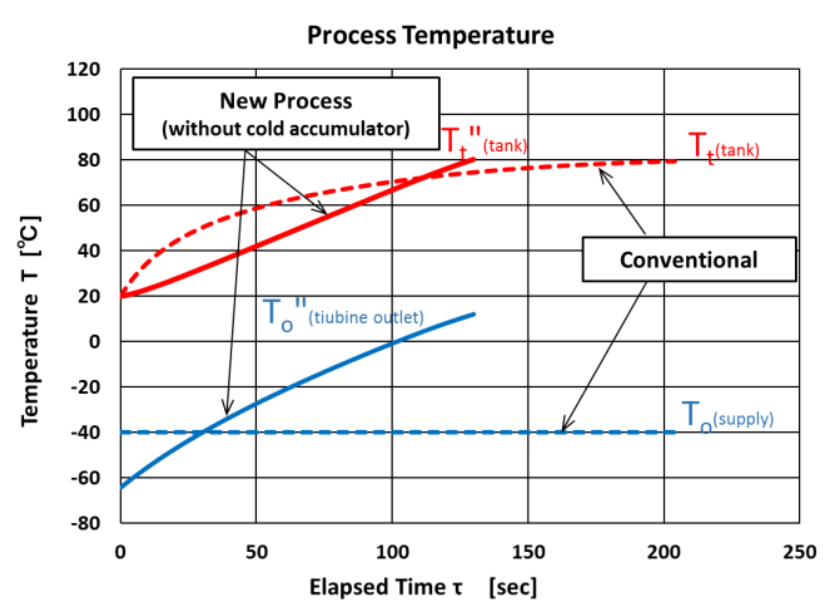

Fig. 7(c) Refueling process temperatures in case without cold accumulator unit

\subsection{Simulation for future system}

As a future refueling process with turbo-expander, we propose an ultimate system without cold accumulator unit, after any low temperature restrictions and regulations are effectively excluded. In this case, turbine outlet gas is supplied as a refueling hydrogen in to the tank directly. Simulated results are shown in Fig. 7(c). The calculation was performed under the same method and conditions as described above.

Figure 7(b) and 7(c) also show that for the conventional case, the gas temperature in the tank rises up to $85^{\circ} \mathrm{C}$ as an exponential shape which shows a steep temperature take-off, while for the new process case, for the system without the cold accumulator unit. In the meanwhile, as shown in Fig. 7(c), the gas temperature behaves relatively lower increasing for starting, and rising up to $85^{\circ} \mathrm{C}$ like in a lineally, corresponding to the decrease in enthalpy drop at the turbine outlet toward the last part. In the early stage of refueling, it is so effective that the lower temperature hydrogen at the turbine outlet works to reduce a rapid temperature uprising like a conventional case.

\subsection{Feasibility study}

Comparing to the conventional pre-cooling system, the new system with turbo-expander has the following feasible advantages as shown in Table 1. 
In the deigned cost estimation, the initial machine cost of the turbo-expander system will be lower than the cost of summation for refrigerator, pre-cooler and, brine piping etc. The significant compactness also has a potential to reduce the cost of dispenser itself with smaller footprint.

For the construction cost at site, evidently, the new system provides much lower expenditure because of its compact unit configuration and provides much shorter period of construction at site. In addition, for the daily operation of the HRS in commercial, cost of electricity is able to be reduced compared to the conventional precooling system with an electrical refrigerator.

Table 1. Comparison of feasibility for $300 \mathrm{Nm}^{3} / \mathrm{h} \mathrm{HRS}$

\begin{tabular}{|l|l|l|}
\hline & \multicolumn{1}{|c|}{ Item } & \multicolumn{1}{c|}{ Evaluation } \\
\hline 1 & Initial Machine Cost & Around $45 \sim 53 \%$ of conventional system. \\
\hline 2 & Construction Cost & $\begin{array}{l}\text { Around } 14 \% \text { of conventional system, because of the significant } \\
\text { compactness. Site construction or piping work is almost eliminated. }\end{array}$ \\
\hline 3 & Operation Cost & Around $13 \%$ of conventional system with electrical refrigerators. \\
\hline 4 & Maintenance Cost & Around $64 \%$ of conventional system \\
\hline
\end{tabular}

\section{Conclusions}

The present paper has proposed a new type of hydrogen refueling system with a turbine expansion unit instead of pre-cooling unit. Thermodynamic simulation on the proposed system has been performed by the same method of prereported simulation codes and thermo-physical property package. The results are summarized as the following.

1. The turbine expanding system for refueling the hydrogen gas applied for HRS has a large advantage and feasibility to the conventional precooling system.

2. A mechanical design of expansion turbine for this new system, tells us that turbine rotor diameter is $10 \mathrm{~mm}$, whose design speed is around 1,000 k-rpm. It was found from the thermodynamic simulation that the turbine adiabatic efficiency is predicted around $65 \%$ for the reasonable process for this system.

For commercialization, we go ahead with manufacturing of prototype turbine unit to verify the effectiveness of the system and testing for matching with refueling protocols thermodynamically.

\section{Acknowledgement}

This thermodynamic process research had been performed by integrated software package of gaseous Hydrogen thermal property, "HYDROGENIUS", developed by Kyusyu University.

\section{Nomenclature}

$\begin{array}{ll}a & : \\ B_{r} & : \\ H & : \\ h_{o}, & : \\ h_{\text {in }} \text { and } h_{\text {out }} & : \\ J_{o} \text { and } Y_{o} & : \\ M_{R} & : \\ m & : \\ m & : \\ P & : \\ P_{\text {in }} & : \\ P_{\text {out }} & : \\ Q & : \\ r & : \\ s & :\end{array}$

Thermal diffusivity $\left[\mathrm{m}^{2} / \mathrm{s}\right]$

Biot number $(=h r / \lambda)[-]$

Heat transfer conductance between inner / outer tube of the cold accumulator $\left[\mathrm{m}^{2} \mathrm{~K} / \mathrm{W}\right]$

Specific enthalpy of tank inlet $[\mathrm{kJ} / \mathrm{kg}]$

Heat transfer coefficient at inside and outside surface $\left[\mathrm{W} / \mathrm{m}^{2} \mathrm{~K}\right]$

Bessel functions [-]

Hydrogen refueled mass [kg]

Mass flow rate of hydrogen (conventional case) in Fig. 7(a) $[\mathrm{kg} / \mathrm{s}]$

Mass flow rate of hydrogen (new process case) in Fig. 7(a) $[\mathrm{kg} / \mathrm{s}]$

Pressure $[\mathrm{Pa}]$

Turbine inlet pressure in Figs. 3(a) and (b) [Pa]

Turbine outlet pressure in Figs. 3(a) and (b) [Pa]

Heat in/ out at the tank reservoir [W]

Radial coordination at the cold accumulator tube [m]

Laplace operator $\left(=s=a q^{2}\right) \quad$ (or specific entropy in Figs. 3(a) and (b)) [-] 


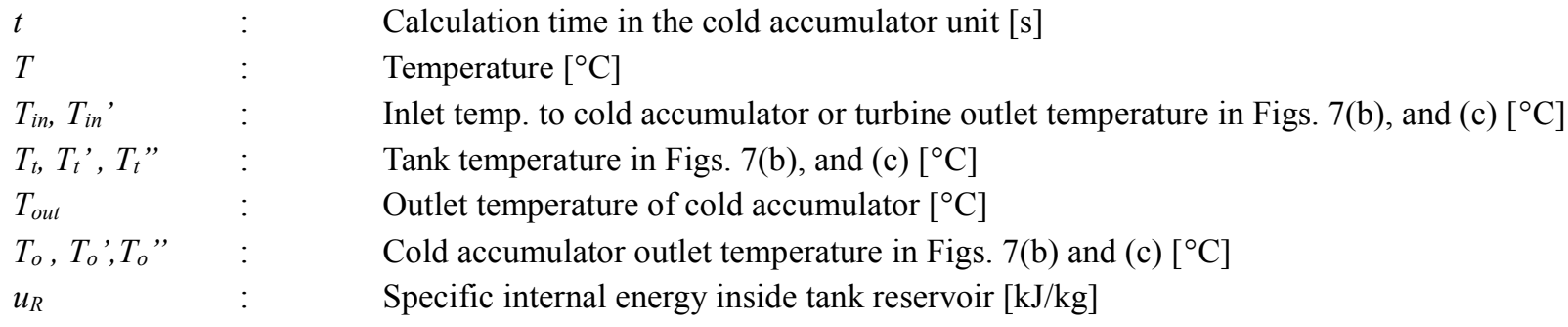

Greek symbols

$\begin{array}{lll}\alpha_{i, n} & : & \text { Eigenvalue }[-] \\ \lambda & : & \text { Thermal conductivity of tubes }[\mathrm{W} / \mathrm{mK}] \\ \theta & : & \text { Temperature }\left(=T-T_{\text {out }}\right)\left[{ }^{\circ} \mathrm{C}\right] \\ \theta_{\mathrm{o}} & : & \text { Temperature }\left(=T_{\text {in }}-T_{\text {out }}\right)\left[{ }^{\circ} \mathrm{C}\right] \\ \tau & : & \text { Calculation time of process simulation }[\mathrm{s}] \\ \eta & : & \text { Turbine adiabatic efficiency }[-]\end{array}$

Subscript

$1,2,3 \quad: \quad$ position of inner and outer tubes

\section{Appendix}

The values of $\alpha_{i, n}$ with $i=1$ or 2 , are determined by the boundary conditions given by Eqs.(3-a) to (3-c) for the inner and outer tubes, respectively. The values of $D_{\mathrm{i}, \mathrm{n}}$ are a function of eigenvalue and can be obtained from the following procedure,

$$
\left.\frac{q_{n}}{2} \frac{d|\Delta(s)|}{d q}\right|_{q=q_{n}}=-\frac{\alpha_{n}}{2} D_{n}, \quad q=i \alpha
$$

The value of $|\Delta(s)|$ in Eq.(A1) is the determinant for an array with an element of $a_{i, j}, i, j=1$ to 4 , given by Table A1. The eigenvalues correspond to the roots of $|\Delta(s)|=0$. The value of $\overline{a_{i, j}}$ is the cofactor for the array with the element of $a_{i, j}$. 
Table A1 Elements of array with $a_{i, j}$ for $H \neq 0$ and $H=0$ in Eq.(5) and Eq.(A-1)

\begin{tabular}{|l|l|l|}
\hline & \multicolumn{1}{|c|}{$H \neq 0$} & \multicolumn{1}{c|}{$H=0$} \\
\hline$a_{1,1}$ & $-\alpha_{1} r_{1} J_{1}\left(\alpha_{1} r_{1}\right)-B r_{1} J_{0}\left(\alpha_{1} r_{1}\right)$ & $-\alpha_{1} r_{1} J_{1}\left(\alpha_{1} r_{1}\right)-B r_{1} J_{0}\left(\alpha_{1} r_{1}\right)$ \\
\hline$a_{1,2}$ & $-\alpha_{1} r_{1} Y_{1}\left(\alpha_{1} r_{1}\right)-B r_{1} Y_{0}\left(\alpha_{1} r_{1}\right)$ & $-\alpha_{1} r_{1} Y_{1}\left(\alpha_{1} r_{1}\right)-B r_{1} Y_{0}\left(\alpha_{1} r_{1}\right)$ \\
\hline$a_{1,3}$ and $a_{1,4}$ & 0 & 0 \\
\hline$a_{2,1}$ & $H\left(J_{0}\left(\alpha_{1} r_{2}\right)-\left(\lambda_{1} \alpha_{1} / H\right) J_{1}\left(\alpha_{1} r_{2}\right)\right)$ & $-\lambda_{1} \alpha_{1} J_{1}\left(\alpha_{1} r_{2}\right)$ \\
\hline$a_{2,2}$ & $H\left(Y_{0}\left(\alpha_{1} r_{2}\right)-\left(\lambda_{1} \alpha_{1} / H\right) Y_{1}\left(\alpha_{1} r_{2}\right)\right)$ & $-\lambda_{1} \alpha_{1} Y_{1}\left(\alpha_{1} r_{2}\right)$ \\
\hline$a_{2,3}$ & $-H J_{0}\left(\alpha_{2} r_{2}\right)$ & $\lambda_{2} \alpha_{2} J_{1}\left(\alpha_{2} r_{2}\right)$ \\
\hline$a_{2,4}$ & $-H Y_{0}\left(\alpha_{2} r_{2}\right)$ & $\lambda_{2} \alpha_{2} Y_{1}\left(\alpha_{2} r_{2}\right)$ \\
\hline$a_{3,1}$ & $H J_{0}\left(\alpha_{1} r_{2}\right)$ & $J_{0}\left(\alpha_{1} r_{2}\right)$ \\
\hline$a_{3,2}$ & $H Y_{0}\left(\alpha_{1} r_{2}\right)$ & $Y_{0}\left(\alpha_{1} r_{2}\right)$ \\
\hline$a_{3,3}$ & $-H\left(J_{0}\left(\alpha_{2} r_{2}\right)+\left(\lambda_{2} \alpha_{2} / H\right) J_{1}\left(\alpha_{2} r_{2}\right)\right)$ & $-J_{0}\left(\alpha_{2} r_{2}\right)$ \\
\hline$a_{3,4}$ & $-H\left(Y_{0}\left(\alpha_{2} r_{2}\right)+\left(\lambda_{2} \alpha_{2} / H\right) Y_{1}\left(\alpha_{2} r_{2}\right)\right)$ & $-Y_{0}\left(\alpha_{2} r_{2}\right)$ \\
\hline$A_{4,1}$ and $a_{4,2}$ & 0 & 0 \\
\hline$a_{4,3}$ & $-\alpha_{2} r_{3} J_{1}\left(\alpha_{2} r_{3}\right)+B r_{2} J_{0}\left(\alpha_{2} r_{3}\right)$ & $-\alpha_{2} r_{3} J_{1}\left(\alpha_{2} r_{3}\right)+B r_{2} J_{0}\left(\alpha_{2} r_{3}\right)$ \\
\hline$a_{4,4}$ & $-\alpha_{2} r_{3} Y_{1}\left(\alpha_{2} r_{3}\right)+B r_{2} Y_{0}\left(\alpha_{2} r_{3}\right)$ & $-\alpha_{2} r_{3} Y_{1}\left(\alpha_{2} r_{3}\right)+B r_{2} Y_{0}\left(\alpha_{2} r_{3}\right)$ \\
\hline
\end{tabular}

\section{References}

Kuroki, T., Sakoda, N., Shinzato, K., Monde, M., Takata, Y., Prediction of transient temperature of hydrogen flowing from pre-cooler of refueling station to inlet of vehicle tank, International Journal of Hydrogen Energy, Vol. 43, No. 3 (2018), pp. 1846-1854.

Monde, M., Mitsutake, Y., Woodfield, P., Maruyama, S., Characteristics of Heat Transfer Increase of Hydrogen during Filling at High Pressure, Transaction of Japan Society of Mechanical Engineers series B, Vol. 72, No.715 (2006), pp. 738-744.

Monde, M., Woodfield, P., Takano, T., Kosada, M., Estimation of temperature change in practical hydrogen pressure tanks being filled at high pressure of 350 and $70 \mathrm{MPa}$, International Journal of Hydrogen Energy, Vo. 37, No. 7 (2012), pp.5723-5734.

Monde, M., Kosada, M., Understanding of Thermal Characteristics of Fuelling Hydrogen High Pressure Tanks and Governing Parameters, SAE International Journal of Alternative Powertrains, vol. 2, No. 1 (2013), pp. 61-67.

Sakoda, N., Akasaka, R., Momoki, S., Yamaguchi, T., Yamaguchi, Shinzato, K., Kohno, M., Takata, Y., Hydrogen thermal properties database compiling a new equation of state and correlations based on the latest experimental data at high temperatures and high pressures, European Hydrogen Energy Conference, Sevilla, Spain, Mar. 12-14, (2014).

SAE-J2601, Hydrogen Fuelling Protocol, revised Dec-2016, Society of Automotive Engineers, (2016).

White Book of Hydrogen Energy (in Japanese), NEDO (Energy and Industrial Technology Development Organization in Japan), (2015).

Woodfield, P., Monde, M., Takano, T., Heat transfer characteristics for Practical Hydrogen Pressure Vessels Being Filled at High Pressure, Journal of Thermal Science and Technology, vol. 3, No. 2 (2008), pp. 241-253. 